Article

\title{
Quasi-Symmetric Transfer Behavior in an Asymmetric Two-Strand Tundish with Different Turbulence Inhibitor
}

\author{
Bin Yang ${ }^{1,2}$, Hong Lei ${ }^{1,2, *}$, Yan Zhao ${ }^{2}$, Guocheng Xing ${ }^{3}$ and Hongwei Zhang ${ }^{1,2}$ \\ 1 Key Laboratory of Electromagnetic Processing of Materials, Ministry of Education, Northeastern University, \\ Shenyang 110004, China \\ 2 School of Metallurgy, Northeastern University, Shenyang 110004, China \\ 3 Dong Bei Special Steel Group CO., LTD., Fushun 113001, China \\ * Correspondence: leihong@epm.neu.edu.cn; Tel.: +86-135-0492-8887
}

Received: 15 July 2019; Accepted: 3 August 2019; Published: 5 August 2019

check for updates

\begin{abstract}
The task of the tundish is to supply and distribute the molten steel with the similar temperature and the similar inclusion mass concentration to the continuous casting mold. But it is difficult for the asymmetric tundish to accomplish this task. Thus, the scheme about the asymmetric turbulence inhibitor and the baffle wall with guided holes is proposed to optimize the tundish. In order to have a deep insight into the metallurgical behavior in the asymmetric tundish, numerical simulation is applied to describe the fluid flow, the heat transfer, RTD (residence time distribution) curve, and inclusion collision aggregation behavior. Numerical results show that the predicted temperature and inclusion concentration agree with the industrial experimental data. In the asymmetric two-strand tundish, the asymmetric turbulence inhibitor and the baffle wall with guided holes can extend the mean residence time at the left outlet, reduce the temperature difference between the two outlets, and prompt the inclusion removal rate at the left outlet.
\end{abstract}

Keywords: asymmetric tundish; asymmetric turbulence inhibitor; inclusion collision aggregation; control device; numerical simulation

\section{Introduction}

As the last refractory reactor, the tundish plays important roles in refining and distributing molten steel to the continuous casting mold. In order to realize such an aim, many flow control devices, such as weirs, dams, impact pads, gas curtains, baffle wall, and turbulence inhibitors have been applied to change the fluid flow, and heat and mass transfer in the tundish [1-3].

In most steelmaking factory, the ladle shroud is placed in the middle of the tundish, so the fluid flow and heat transfer is symmetric in the tundish. But there are some asymmetric two-strand tundishes in China for some historical reasons, and they have their own metallurgical characteristics. In order to exploit the equipment potential, it is necessary to propose some effective measurements to obtain the quasi-symmetric field in the asymmetric tundish without changing tundish structure. In other words, the optimized tundish should ensure that the molten steel at different tundish outlets has similar temperature and similar inclusion mass concentration.

During the process of optimizing the tundish structure, water model, numerical simulation, and industrial experiment are three effective methods. They have their own advantages and disadvantages.

(1) Water model is the most popular approach for studying the fluid flow, the heat transfer, and the inclusion behavior [4-10] in the tundish because of low cost, convenient operation, and safety. 
But usually, only one dimensionless number (Froude number) is applied to satisfy the similarity criterion, so the experimental data cannot give an accurate description of metallurgical phenomena in the tundish.

(2) Numerical simulation is a more and more popular method to have a deep insight into the metallurgical phenomena because it can give detailed information about the metallurgical process [11-20]. But some assumptions are applied in the mathematical model in order to simplify the governing equations.

(3) Industrial experiment is the most effective method to study metallurgical behavior [21-23]. But the high-temperature environment, high costs, and less data limit its application.

In the present work, a three-dimensional numerical simulation is applied to give the quantitative analysis for the original and optimized tundish at first. The key factors include the flow field, the temperature field, the RTD (residence time distribution) curve, and the inclusion field, as shown in Figure 1. Then, an industrial experiment is conducted to evaluate the metallurgical characteristics in the original tundish and optimized tundish.

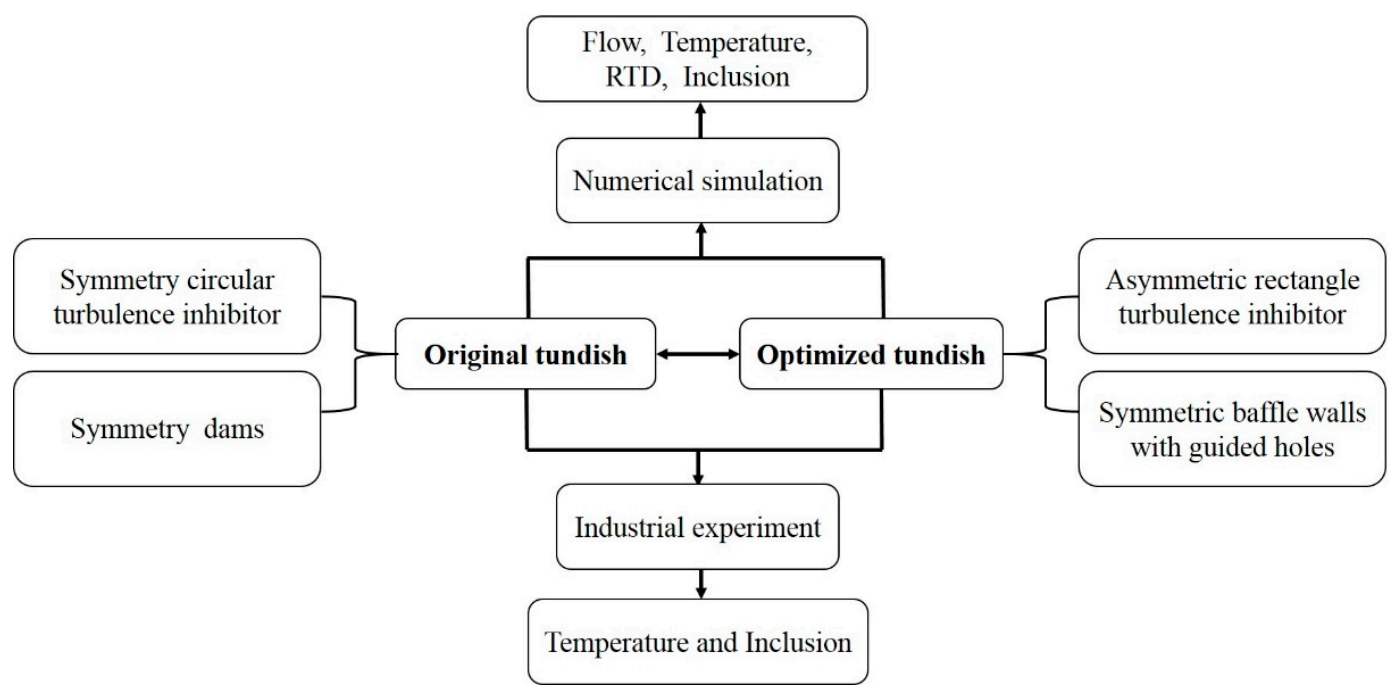

Figure 1. Optimize the physical field for an asymmetric tundish.

\section{Tundish Description}

Figure 2 gives the geometry of the original and optimized tundish. This is a two-strand asymmetric tundish. The ladle shroud is close to outlet 1 , and is far away from outlet 2 , and the turbulence inhibitor is just below the ladle shroud. The original tundish consists of a circular turbulence inhibitor and two dams, and the optimized tundish has an asymmetric rectangle turbulence inhibitor and two multi-hole baffle walls. The geometric and physical parameters for the model tundish are described in the Table 1 .

Table 1. Parameters in the model tundish.

\begin{tabular}{cc}
\hline Parameters & Model Tundish \\
\hline Number of strand & 2 \\
Length of upper longitudinal side $(\mathrm{mm})$ & 7128 \\
Length of lower longitudinal side $(\mathrm{mm})$ & 6780 \\
Length of lower width side $(\mathrm{mm})$ & 1007 \\
Length of upper width side $(\mathrm{mm})$ & 590 \\
Tundish depth $(\mathrm{mm})$ & 1000 \\
Volume flow of inlet $\left(\mathrm{m}^{3} / \mathrm{s}\right)$ & 0.012 \\
Diameter of inlet $\left(\mathrm{mm}^{\mathrm{s}}\right)$ & 140 \\
Diameter of outlet $(\mathrm{mm})$ & 80 \\
Diameter of guided holes $(\mathrm{mm})$ & 165 \\
Distance between guided holes $(\mathrm{mm})$ & 285 \\
\hline
\end{tabular}




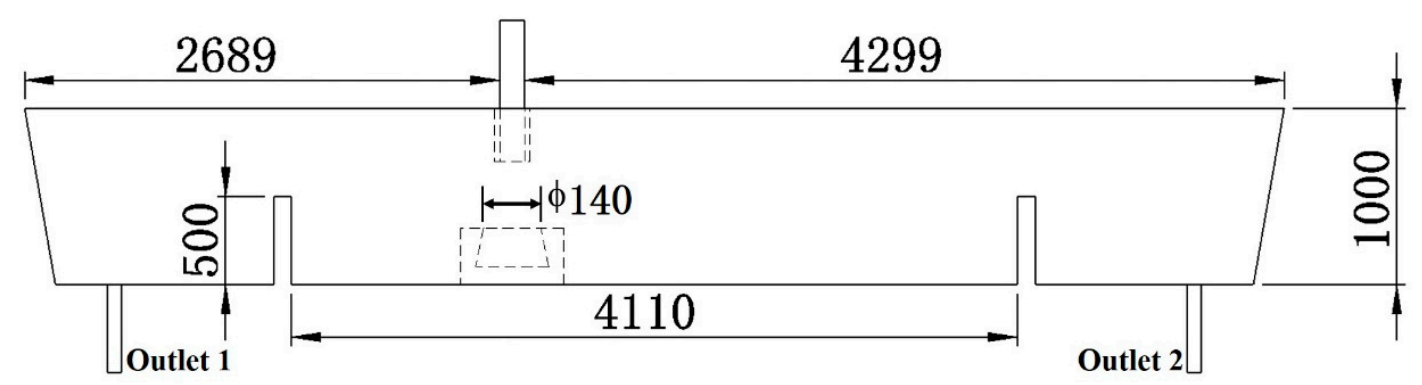

(a) Original tundish

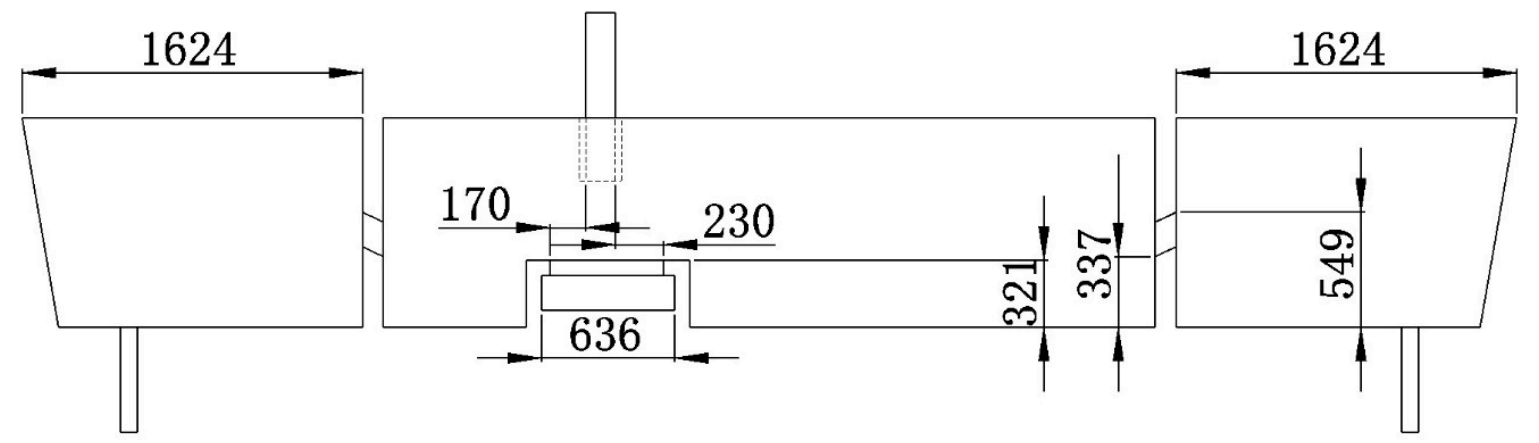

(b) Optimized tundish

Figure 2. Tundish structure (all dimensions are in $\mathrm{mm}$ ).

\section{Mathematical Model}

\subsection{Assumption}

(1) The molten steel is an incompressible Newtonian fluid, and the fluid flow in the tundish is at a stable state.

(2) The free surface is flat in the tundish.

(3) The inclusion is identified as a sphere.

(4) The effect of inclusion on the fluid flow is negligible because the inclusion mass fraction is too low.

(5) The inclusions are removed once they touch the tundish wall or the slag layer.

(6) Inclusion phase is treated as a continuous phase.

(7) Brownian collision among inclusions is too weak to be considered.

(8) There is no chemical reaction in the tundish.

(9) The heat transfer and the inclusion collision aggregation are at the stable state.

\subsection{Fluid Flow, Heat Transfer and Solute Transport}

The fluid flow, the heat transfer, and the tracer transport in the tundish can be described as the following equations [24].

$$
\begin{gathered}
\nabla \cdot \vec{u}_{\mathrm{f}}=0 \\
\nabla \cdot\left(\rho \vec{u}_{\mathrm{f}} \vec{u}_{\mathrm{f}}\right)=-\nabla p+\rho \vec{g}+\nabla \cdot\left[\mu_{\mathrm{eff}}\left(\nabla \vec{u}_{\mathrm{f}}+\left(\nabla \vec{u}_{\mathrm{f}}\right)^{\mathrm{T}}\right)\right]+\beta\left(T_{0}-T\right) \rho \vec{g} \\
\frac{\partial\left(\rho C_{\mathrm{p}} T\right)}{\partial t}+\nabla \cdot\left(\rho T \vec{u}_{\mathrm{f}}\right)=\nabla \cdot\left(\lambda_{\mathrm{eff}} \nabla T\right), \\
\frac{\partial(\rho \varphi)}{\partial t}+\nabla \cdot\left(\rho \vec{u}_{\mathrm{f}} \varphi\right)=\nabla \cdot\left(\rho D_{\mathrm{eff}} \nabla \varphi\right),
\end{gathered}
$$

where $\vec{u}_{\mathrm{f}}$ is the velocity of molten steel, $\rho$ is the density of liquid, $\vec{g}$ is the gravitational acceleration vector, $p$ is the pressure, $\mu_{\text {eff }}$ is the effective viscosity coefficient, $C_{p}$ is the heat capacity, $T$ is the temperature of liquid, $D_{\text {eff }}$ is the effective diffusion coefficient, $\varphi$ is the tracer mass concentration, $T_{0}$ is 
the reference temperature, the turbulent viscosity $\mu_{\text {eff }}$ is determined by the standard $k-\varepsilon$ two equations model, $\beta$ is the coefficient of thermal expansion.

During the numerical simulation, a volume of 200 milliliter tracer is introduced as a whole and is injected into the tundish through the ladle shroud by pluse form, and the tracer concentration at two tundish outlets is recorded continuously. In this way, the curve of tracer concentration at the outlet against the time is the residence time distribution (RTD) curve. During the calculation, the physical parameters of the tracer are the same as those of the molten steel. And the classic combined [24] model is applied to analyze the RTD curve and to give the plug zone $\left(\mathrm{V}_{\mathrm{pv}}\right)$, the well-mixed zone $\left(\mathrm{V}_{\mathrm{mv}}\right)$, and the dead zone $\left(\mathrm{V}_{\mathrm{dv}}\right)$ of the tundish.

\subsection{Inclusion Collision-Coalescence Model}

The inclusion mass and population conservation model [25-27], which are verified by the industrial experiment [26] are applied to describe the inclusion collision-aggregation in the tundish.

$$
\begin{gathered}
\nabla \cdot\left(\rho_{\mathrm{f}} \vec{u}_{\mathrm{C}} C\right)=\nabla \cdot\left(\rho_{\mathrm{f}} D_{\mathrm{eff}, \mathrm{C}} \nabla C\right), \\
\nabla \cdot\left(\rho_{\mathrm{f}} \vec{u}_{\mathrm{N}} N\right)=\nabla \cdot\left(\rho_{\mathrm{f}} D_{\mathrm{eff}, \mathrm{N}} \nabla N\right)+S_{\mathrm{N}},
\end{gathered}
$$

with $D_{\text {eff }}=D_{0}+\mu_{\mathrm{t}} / \rho_{\mathrm{f}} S c_{\mathrm{t}}$.

In Equation (6), the source term $S_{\mathrm{N}}$ is related to the inclusion collision-coalescence in the molten steel [27].

$$
S_{\mathrm{N}}=S_{\text {turb }}+S_{\text {Stokes }}=2.6 \alpha\left(\frac{\pi \rho_{\mathrm{f}} \varepsilon}{\mu_{1}}\right)^{0.5} N^{2} r *^{3}+\frac{10}{9 \sqrt[3]{6}} \frac{\pi \vec{g} \Delta \rho}{\mu_{1}} N^{2} r *^{4}
$$

where $r *=\sqrt[3]{\frac{3 C}{4 \pi N}}$ is the characteristic inclusion radius, $\vec{u}_{\mathrm{C}}$ and $\vec{u}_{\mathrm{N}}$ are the inclusion slipping velocity, $C$ is the inclusion volume concentration, $N$ is the inclusion number density, $D_{0}$ is molecular diffusion coefficient, $\mu_{\mathrm{t}}$ is the turbulence viscosity, $S c_{\mathrm{t}}$ is the turbulent Schmidt number, $S_{\mathrm{N}}$ is the source of inclusion number density, $\mu_{1}$ is the kinematic viscosity, $\varepsilon$ is the turbulence dissipation rate.

\subsection{Boundary Conditions}

The boundary conditions for the fluid flow are listed as follows:

(1) No-slip condition is applied at the tundish wall, and the scalable wall function method is applied near the wall.

(2) The free-slip condition is applied at the free surface.

(3) The full-developed condition is applied at the tundish exit.

The other boundary conditions can be found in Tables 2-4.

Table 2. Boundary conditions of inclusion $[25,26]$.

\begin{tabular}{ccc}
\hline Parameter & $\mathbf{C}$ & $\mathbf{N}$ \\
\hline Inlet & $C_{0}$ & $N_{0}$ \\
\hline Outlet & $\frac{\partial C}{\partial n}=0$ & $\frac{\partial N}{\partial n}=0$ \\
\hline Tundish wall and free surface & $F_{\mathrm{C}}^{\mathrm{c}}+F_{\mathrm{C}}^{\mathrm{d}}$ & $F_{\mathrm{N}}^{\mathrm{c}}+F_{\mathrm{N}}^{\mathrm{d}}$ \\
\hline
\end{tabular}

Table 3. Initial and boundary condition for tracer transport.

\begin{tabular}{ccccc}
\hline Time & Inlet & Wall & Outlet & Free surface \\
\hline $\mathrm{t}=0$ & $\phi=\phi_{0}$ & $\frac{\partial \phi}{\partial n}=0$ & $\frac{\partial \phi}{\partial n}=0$ & $\frac{\partial \phi}{\partial n}=0$ \\
\hline $\mathrm{t}>0$ & $\frac{\partial \phi}{\partial n}=0$ & $\frac{\partial \phi}{\partial n}=0$ & $\frac{\partial \phi}{\partial n}=0$ & $\frac{\partial \phi}{\partial n}=0$ \\
\hline
\end{tabular}


Table 4. Physical parameters and boundary conditions [28-30].

\begin{tabular}{cc}
\hline Parameter & Value \\
\hline Free surface heat loss $\left(\mathrm{W} / \mathrm{m}^{2}\right)$ & 75,000 \\
Bottom heat loss $\left(\mathrm{W} / \mathrm{m}^{2}\right)$ & 8000 \\
Wide wall heat loss $\left(\mathrm{W} / \mathrm{m}^{2}\right)$ & 4000 \\
Narrow wall heat loss $\left(\mathrm{W} / \mathrm{m}^{2}\right)$ & 4000 \\
Channel wall heat loss $\left(\mathrm{W} / \mathrm{m}^{2}\right)$ & 8000 \\
Thermal conductivity of liquid steel $(\mathrm{W} /(\mathrm{m} \cdot \mathrm{K}))$ & 41 \\
Heat capacity of liquid steel $(\mathrm{J} /(\mathrm{kg} \cdot \mathrm{K}))$ & 750 \\
Inlet velocity $(\mathrm{m} / \mathrm{s})$ & 0.773 \\
Inlet temperature $(\mathrm{K})$ & 1873 \\
Density of liquid steel $\left(\mathrm{kg} / \mathrm{m}^{3}\right)$ & $(8523-0.8358 T)$ \\
Coefficient of thermal expansion of liquid steel $(1 / \mathrm{K})$ & 0.0001 \\
Viscosity of the molten steel $(\mathrm{kg} /(\mathrm{m} \cdot \mathrm{s}))$ & 0.0061 \\
\hline
\end{tabular}

\subsection{Numerical Solution}

ANSYS CFX software (Version 11.0, ANSYS, Pittsburgh, PA, USA, 2008) is applied to solve these partial differential equations in order to obtain the flow field, the temperature field, the tracer field, and the inclusion field. The calculation domain is covered by about 200,000 hexahedral grids. The convergence criteria is that the normalized residual for variables should be less than $10^{-5}$. Figure 3 gives the numerical solution process.

(1) The fluid flow model and the heat transport model are coupled to obtain the flow field and the temperature field.

(2) On the basis of the known flow field, the tracer transport equation is solved to obtain the RTD curve.

(3) On the basis of the known flow field, the inclusion collision-coalescence model is solved to obtain the spatial distribution of inclusion volume concentration, inclusion number density, and inclusion characteristic radius.

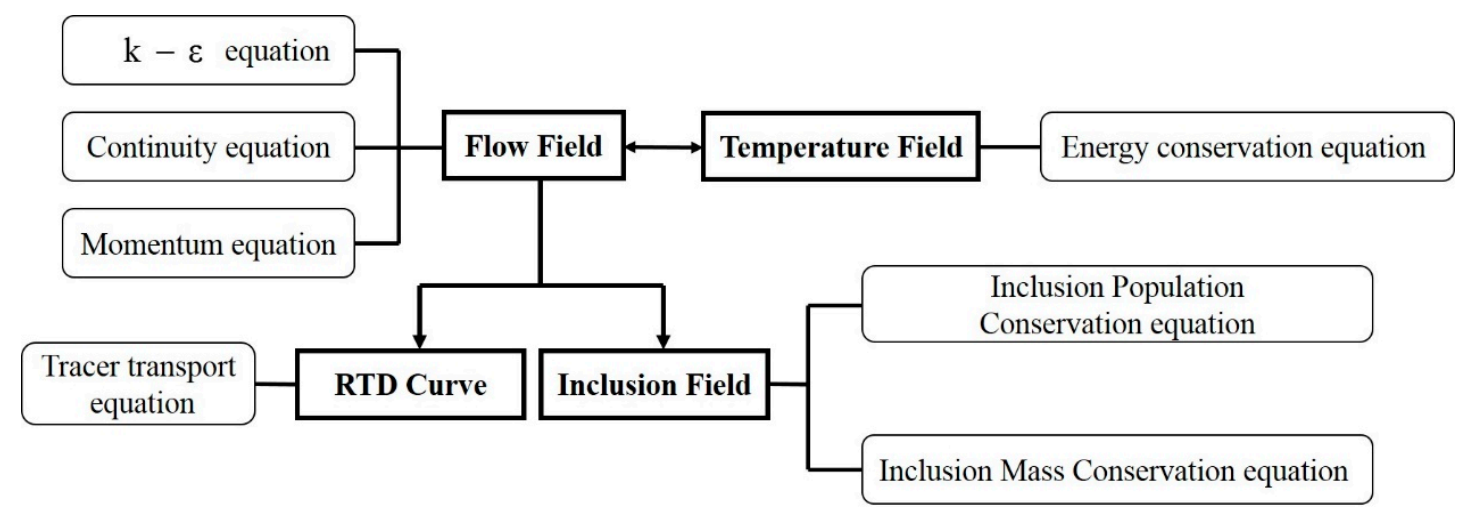

Figure 3. The numerical solution process.

\section{Results and Discussion}

This tundish is an asymmetric tundish. Figure 4 shows that the ladle shroud is not in the middle of the two outlets and is close to the left outlet (outlet 1). In order to describe the physical field in the tundish clearly, it is necessary to define two specified cross sections, shown in Figure 4. Section A-A $(Y=0)$, which passes through the center line of the ladle shroud and the center line of the tundish outlet, is the longitudinal symmetrical plane of the tundish, and section B-B $(Y=0.14)$, which passes through the center line of the guide hole of the baffle wall and is parallel to the section A-A, is the longitudinal cross plane. 


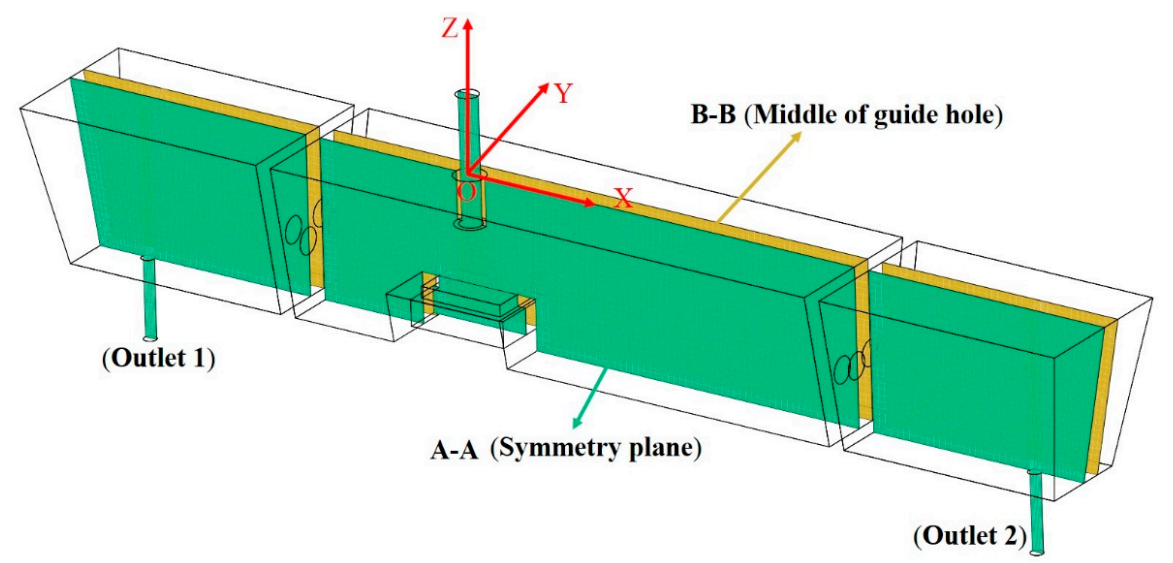

Figure 4. Characteristic sections in the tundish.

\subsection{Fluid Flow}

Figure 5 shows that the velocity field in the original tundish has the following characteristics: (1) There is a vortex on both sides of the ladle shroud. The left vortex is circular and the right vortex is elliptical, because the ladle shroud is close to the left dam and is far away from the right dam. (2) The fluid bypasses the dam and forms a big recirculation zone above outlet 1. (3) The velocity of molten steel at the free surface at the left side of the ladle shroud (maximum velocity is $0.06 \mathrm{~m} / \mathrm{s}$ ) is greater than that at the right side of the ladle shroud (maximum velocity is $0.04 \mathrm{~m} / \mathrm{s}$ ) because of the longer distance between shroud and right dam.

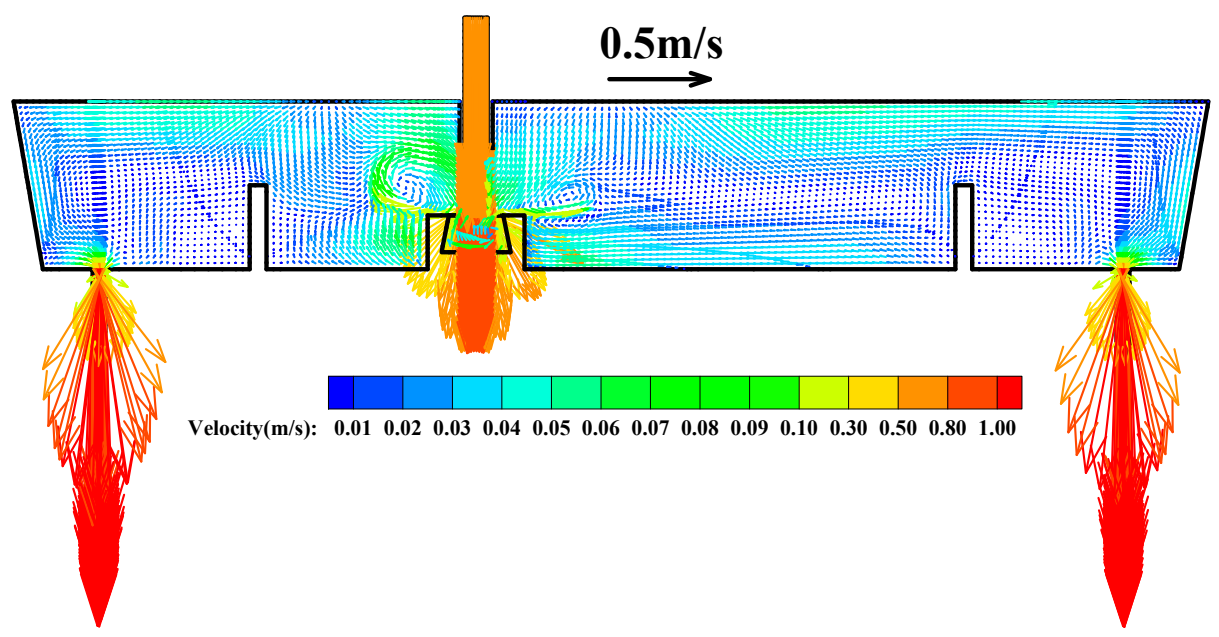

(a) A-A Section

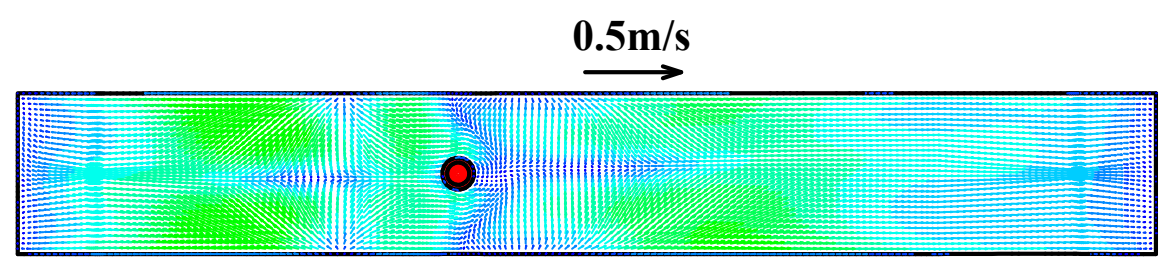

$\begin{array}{llllllllllllllll}\text { Velocity }(\mathrm{m} / \mathrm{s}): & 0.01 & 0.02 & 0.03 & 0.04 & 0.05 & 0.06 & 0.07 & 0.08 & 0.09 & 0.10 & 0.11 & 0.12 & 0.13 & 0.14 & 0.15\end{array}$

(b) Free surface

Figure 5. Fluid flow in the original tundish. 
Figure 6 gives several new flow characteristics in the optimized tundish: (1) There are asymmetric vortices on both side of the main stream from the ladle shroud in the turbulence inhibitor, and the right vortex is bigger than the left vortex, because the centerline of ladle shroud is at the left side of the centerline of the turbulence inhibitor. (2) The fluid flow near the left outlet is similar to that near the right outlet because of the isolation of the baffle walls. (3) The steel stream from the ladle shroud impinges on the bottom of the turbulence inhibitor, and then flows upwards to the free surface. (4) The asymmetric rectangle turbulence inhibitor changes the flow distribution on the left and right sides of the ladle shroud. Specifically, the flow rate of molten steel on the right side of the turbulence inhibitor is greater than that on the left side. Such a flow distribution by the asymmetric turbulence inhibitor can force the quasi-symmetry of the flow field in the asymmetric tundish.

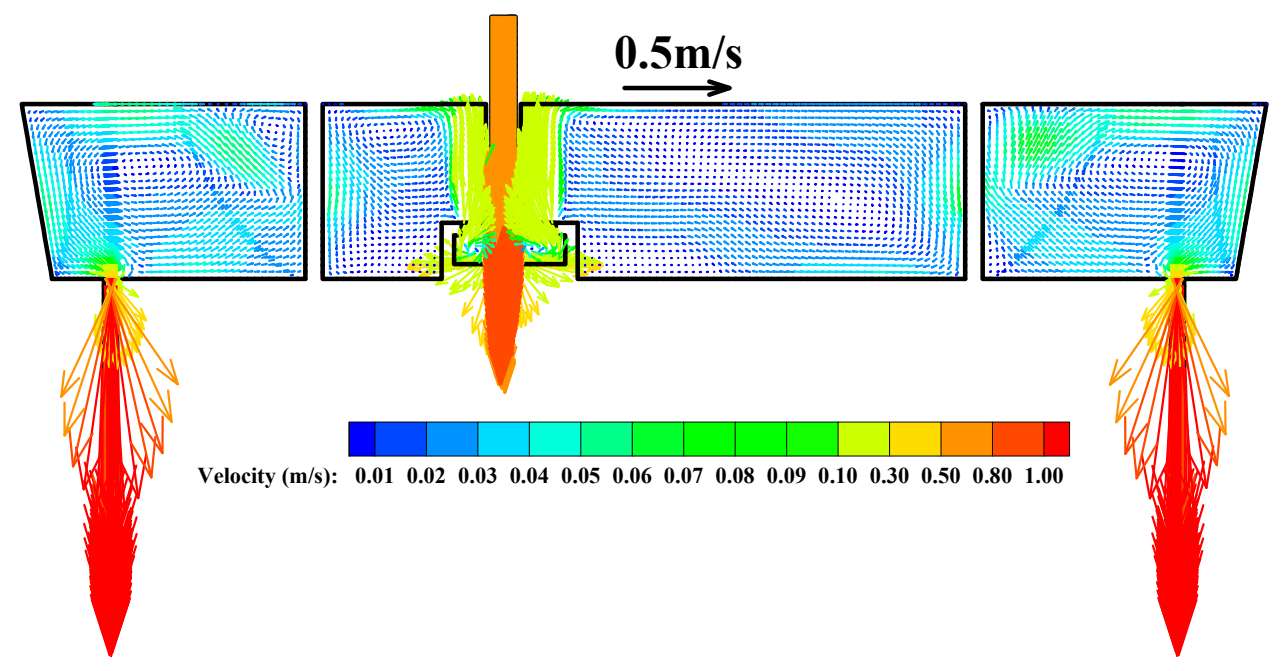

(a) A-A Section

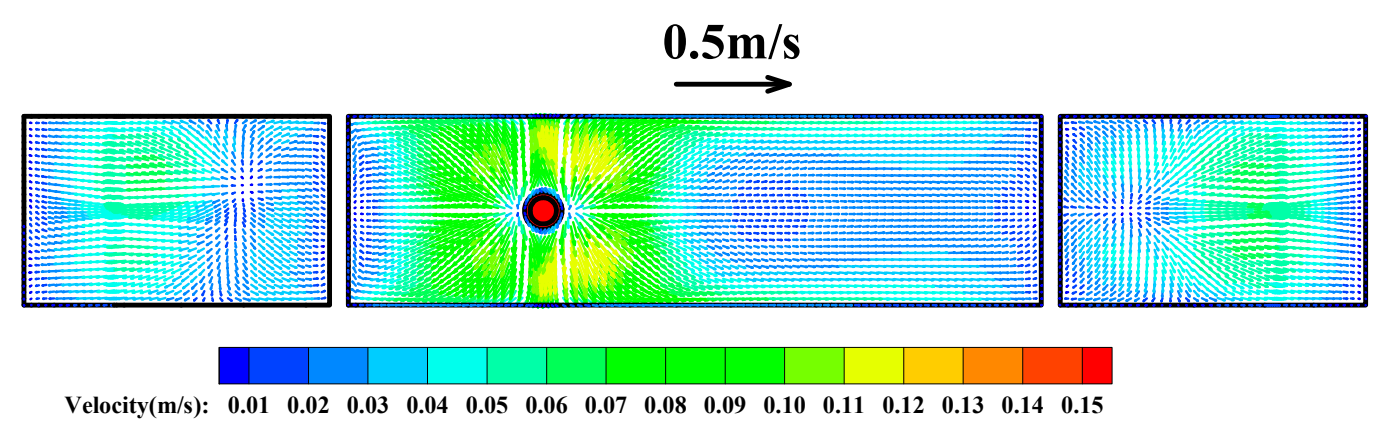

(b) Free surface

Figure 6. Fluid flow in the optimized tundish.

\subsection{RTD Curve}

Figure 7 gives the RTD curves for the original and optimized tundish. For the original tundish, the difference of maximum concentration between the two outlets is $89.9 \%$, but the difference falls by $20.8 \%$ for the optimized tundish.

Table 5 gives the analysis result of RTD curve for the original and optimized tundish. It has the following features. (1) The dead volume fraction is negative for the outlet 2 in the original and optimized tundish, because it is meaningless to calculate the plug volume, the well-mixed volume, and the dead volume at each outlet in the multi-strand tundish [31]. (2) The mean residence time at each outlet is the key to estimate the similarity of fluid flow among strands [31]. The mean residence time of $352.4 \mathrm{~s}$ at the outlet 1 in the optimized tundish is $36.8 \mathrm{~s}$ greater than $315.6 \mathrm{~s}$ at the outlet 1 in the original tundish. And the difference of the mean residence time between the two outlets falls by $10.0 \%$, 
from $203.8 \mathrm{~s}$ to $183.5 \mathrm{~s}$ after optimization. (3) The difference of the minimum residence time of $98 \mathrm{~s}$ between the two outlets in the optimized tundish is $40 \mathrm{~s}$ more than of $58 \mathrm{~s}$ in the original tundish, and the difference of the maximum time between the two outlets in the optimized tundish of $167 \mathrm{~s}$ is $100 \mathrm{~s}$ less than that in the original tundish.

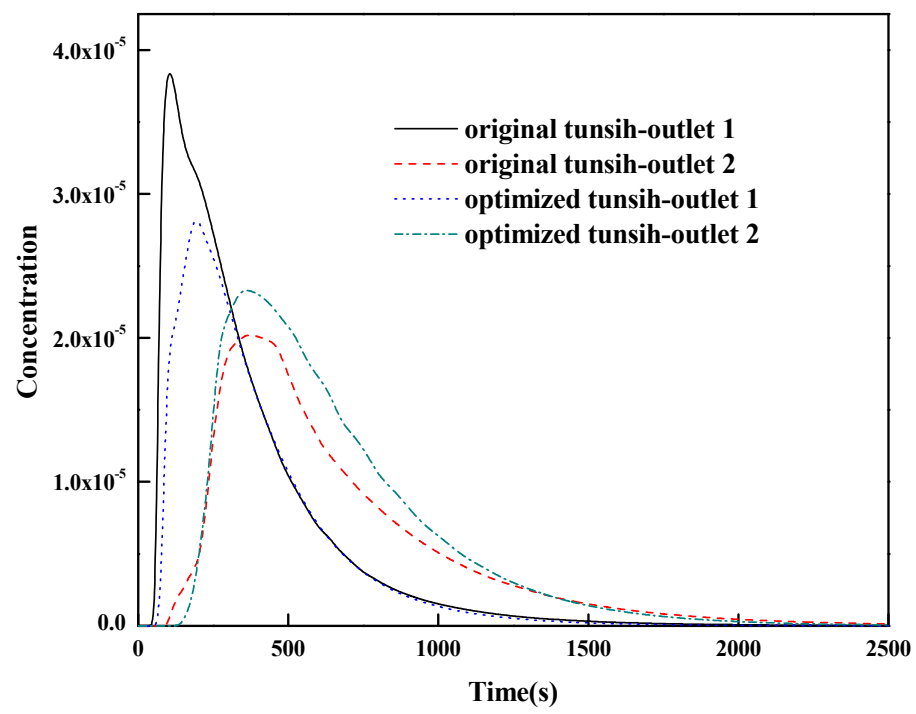

Figure 7. RTD (residence time distribution) curves in the tundish.

Table 5. Fluid flow characteristics in the original and optimized tundish.

\begin{tabular}{|c|c|c|c|c|c|c|c|c|c|}
\hline \multirow{2}{*}{ Tundish } & \multicolumn{3}{|c|}{ Time (s) } & \multirow{2}{*}{$\frac{\Delta t_{\min }}{t_{\min 2}-t_{\min 1}}$} & \multirow{2}{*}{$\frac{\Delta t_{\max }}{t_{\max 2}-t_{\max 1}}$} & \multirow{2}{*}{$\frac{\Delta t_{\mathrm{av}}}{t_{\mathrm{av} 2}-t_{\mathrm{av} 1}}$} & \multicolumn{3}{|c|}{ Volume Fraction (\%) } \\
\hline & $t_{\min }$ & $t_{\max }$ & $t_{\mathrm{av}}$ & & & & $V_{\mathrm{d}}$ & $V_{\mathrm{m}}$ & $V_{\mathrm{p}}$ \\
\hline Original outlet 1 & 54.0 & 105.0 & 315.6 & \multirow{2}{*}{58} & \multirow{2}{*}{267} & \multirow{2}{*}{203.8} & 29.2 & 53.0 & 17.8 \\
\hline Original outlet 2 & 112.0 & 372.0 & 519.4 & & & & -16.5 & 62.2 & 54.3 \\
\hline Optimized outlet 1 & 69.0 & 194.0 & 352.4 & \multirow{2}{*}{98} & \multirow{2}{*}{167} & \multirow{2}{*}{183.5} & 20.9 & 49.6 & 29.5 \\
\hline Optimized outlet 2 & 167.0 & 361.0 & 535.9 & & & & -20.2 & 61.0 & 59.2 \\
\hline
\end{tabular}

\subsection{Heat Transfer}

Figures 8 and 9 give the following features about the temperature field in the original tundish and optimized tundish. (1) In the original tundish, the temperature gradient on both sides is greater than that between the two dams because of the insufficient isolation of a low dam. In the optimized tundish, the temperature gradient on both sides is less than that between the two baffle walls because of the effective isolation of baffle wall. (2) Because of the shorter distance between the ladle shroud and the left outlet, the temperature of $1864.9 \mathrm{~K}$ at the left outlet in the original tundish is $6.8 \mathrm{~K}$ greater than $1858.1 \mathrm{~K}$ at right outlet in the original tundish. (3) In the optimized tundish, the temperature of $1863.8 \mathrm{~K}$ at the left outlet 1 is only $4.5 \mathrm{~K}$ greater than $1859.3 \mathrm{~K}$ at right outlet 2, because the asymmetric rectangle turbulence inhibitor changes the flow distribution of molten steel at the left and right sides of the ladle shroud. 


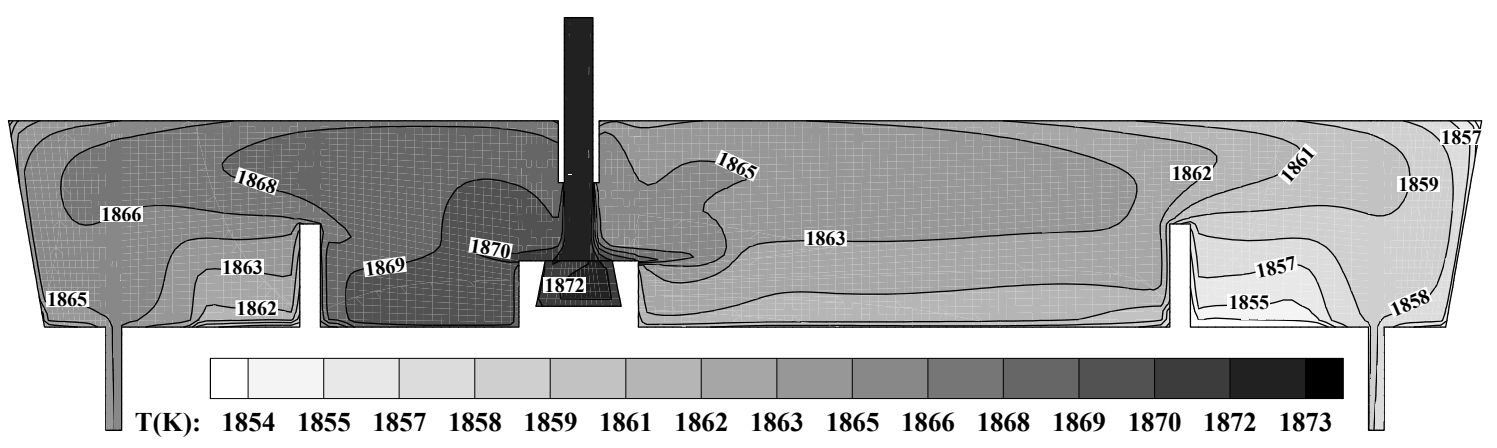

(a) A-A Section

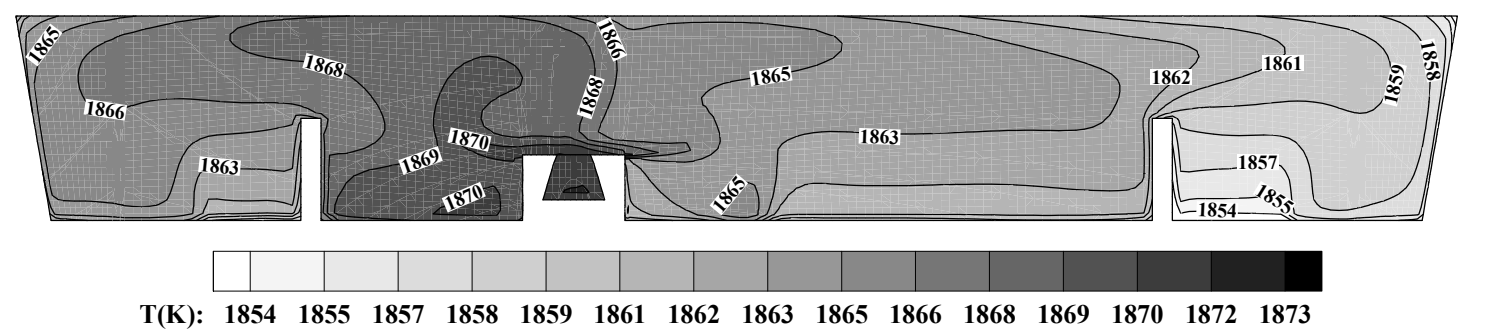

(b) B-B Section

Figure 8. Temperature field in the original tundish.

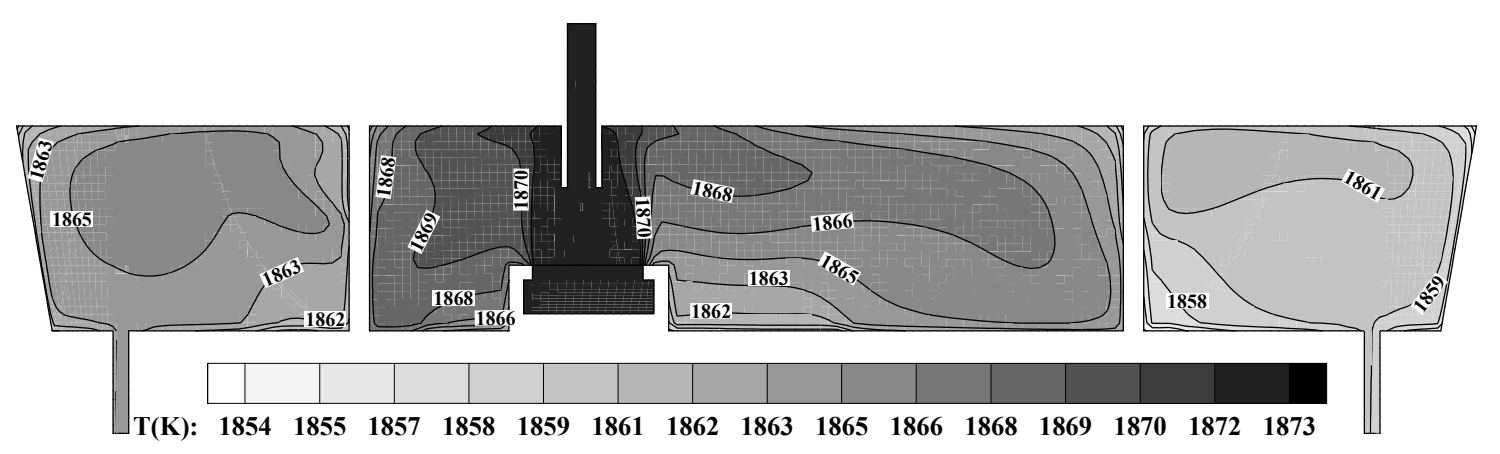

(a) A-A Section

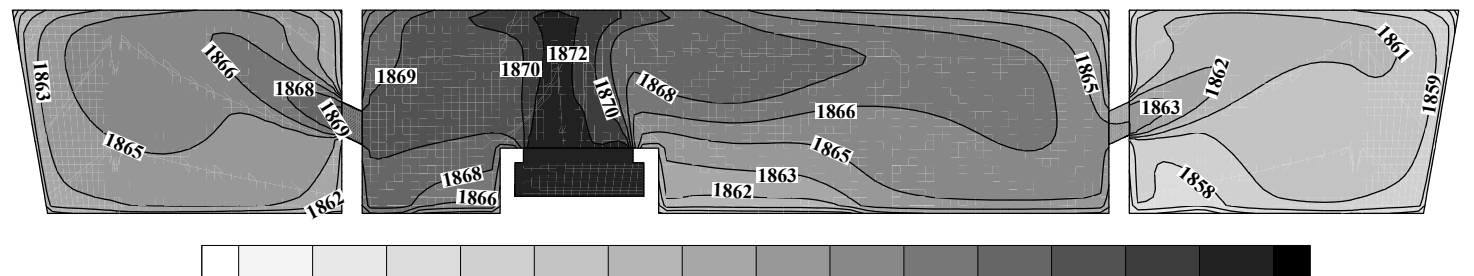

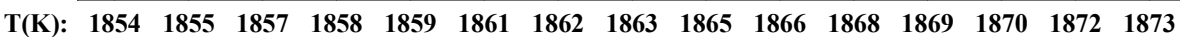

(b) B-B Section

Figure 9. Temperature field in the optimized tundish.

\subsection{Inclusion Field}

Figures 10 and 11 show that the inclusion volume concentration in the original and optimized tundish has the following features: (1) The inclusion volume concentration is asymmetric in the original and optimized tundish. (2) The inclusion volume concentration gradually decreases from the ladle shroud to the tundish outlet, because the inclusions in the molten steel are removed by the tundish wall and the slag layer continuously. (3) The inclusion volume concentration on the left side is greater than that on the right side because there is a longer distance between the ladle shroud and the right outlet and the inclusions have more time to float up and to be removed. (4) The optimized tundish can 
reduce the difference of inclusion between the right outlet and the left outlet. The inclusion volume concentration of $209.25 \mathrm{ppm}$ at the left outlet is greater than the $139.16 \mathrm{ppm}$ at the right outlet in the original tundish. And the inclusion volume concentration of $194.57 \mathrm{ppm}$ at the left outlet is greater than $145.59 \mathrm{ppm}$ at the right outlet in the optimized tundish.

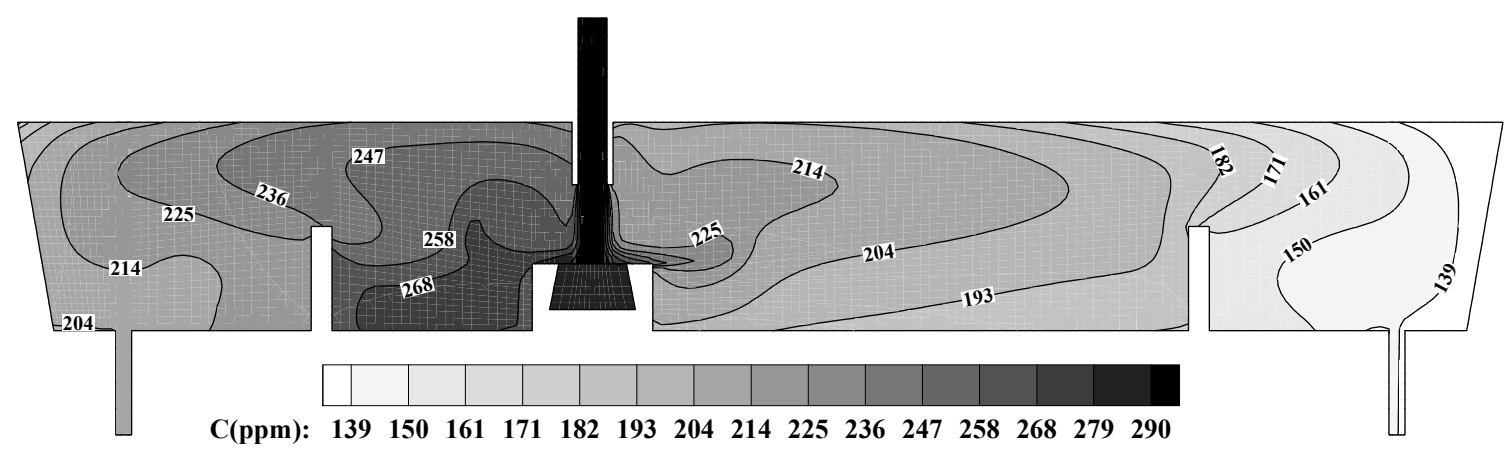

(a) A-A Section

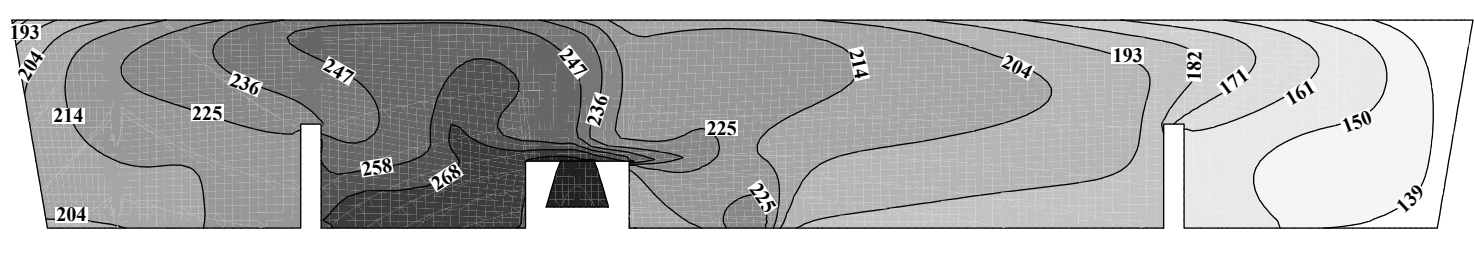

C(ppm): $\begin{array}{llllllllllllllll}139 & 150 & 161 & 171 & 182 & 193 & 204 & 214 & 225 & 236 & 247 & 258 & 268 & 279 & 290\end{array}$

(b) B-B Section

Figure 10. Inclusion volume concentration distribution in the original tundish.

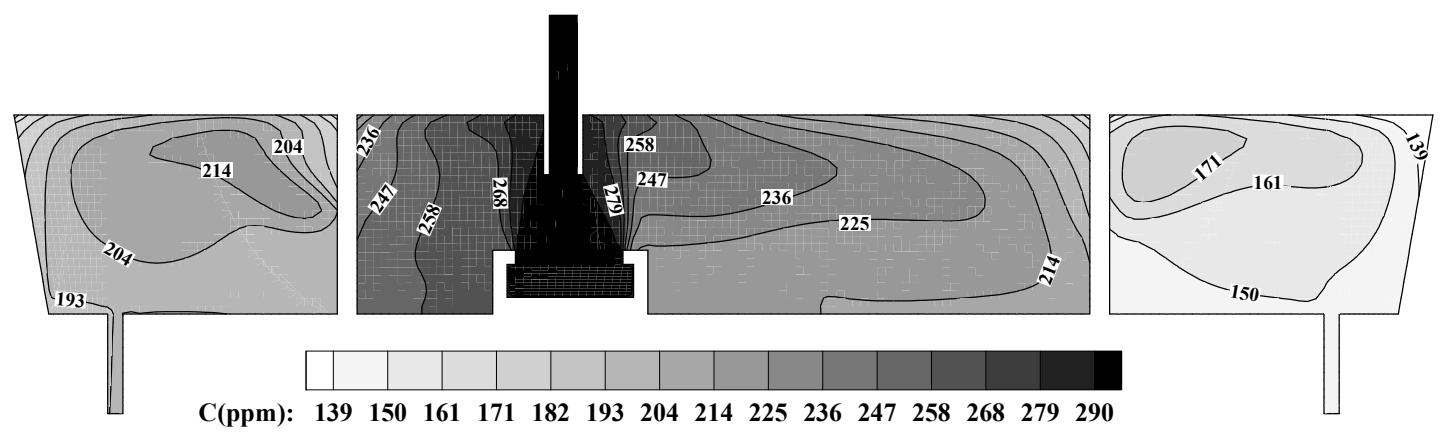

(a) A-A Section

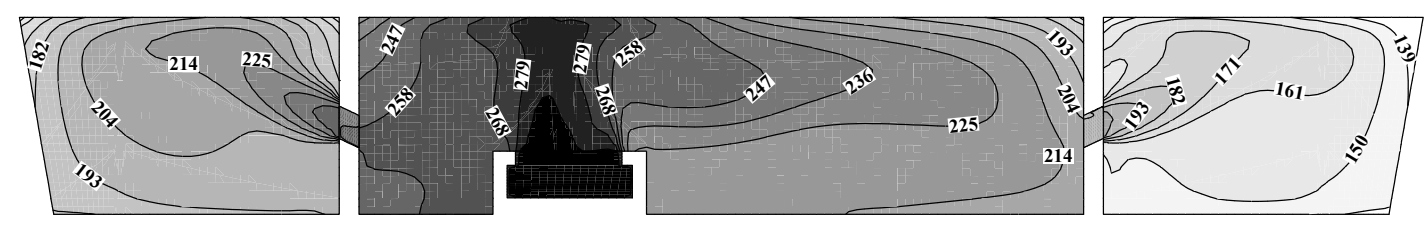

C(ppm): $139 \begin{array}{lllllllllllllll}150 & 161 & 171 & 182 & 193 & 204 & 214 & 225 & 236 & 247 & 258 & 268 & 279 & 290\end{array}$

(b) B-B Section

Figure 11. Inclusion volume concentration distribution in the optimized tundish.

Figures 12 and 13 show that the inclusion characteristic radius in the original tundish and optimized tundish has some remarkable features: (1) The inclusion characteristic radius increases gradually when the fluid flows from the ladle shroud to the tundish outlet due to the collision 
aggregation among the inclusions. (2) In the region between the dam (or the multi-hole baffle wall) and outlet, the inclusion in the lower part is bigger than that in the upper part, because the bigger inclusions in the upper zone have more chances to be removed by the slag layer, and the smaller inclusions in the lower zone have more chances to be removed by the tundish wall. (3) The inclusion characteristic radius above the right outlet is greater than that above the left outlet, because the inclusions on the right side of the ladle shroud have more chances to collide aggregate. (4) The inclusion characteristic radius at the left outlet is less than that at the right outlet for the two tundish.

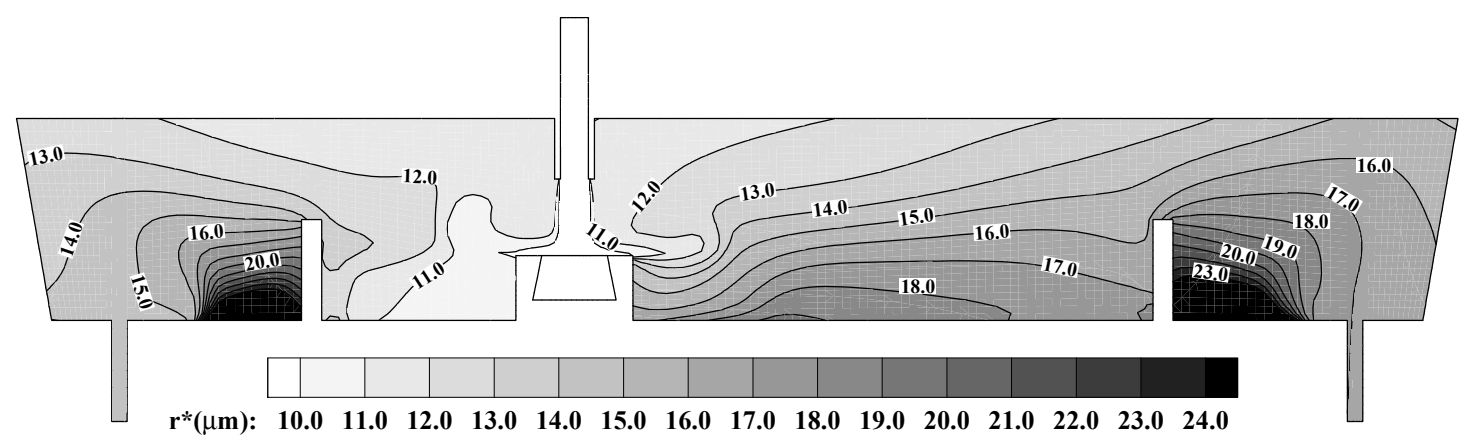

(a) A-A Section
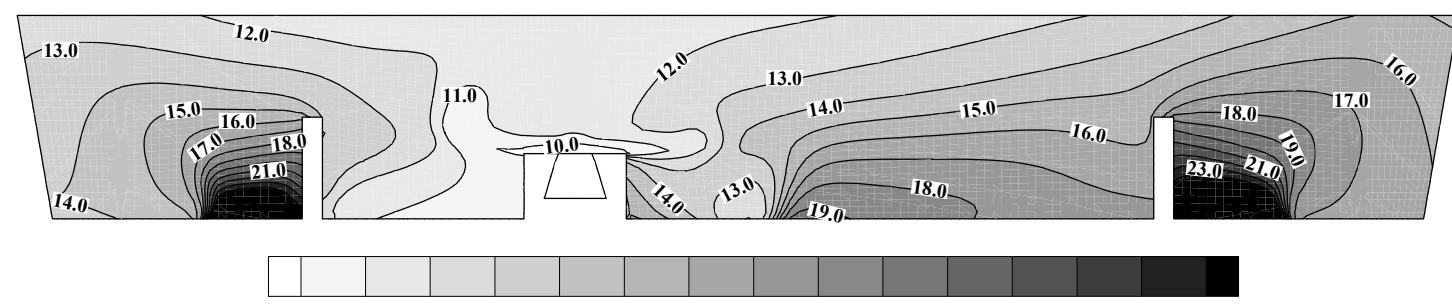

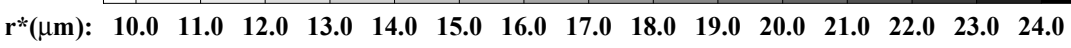

(b) B-B Section

Figure 12. Characteristic inclusion radius in the original tundish.

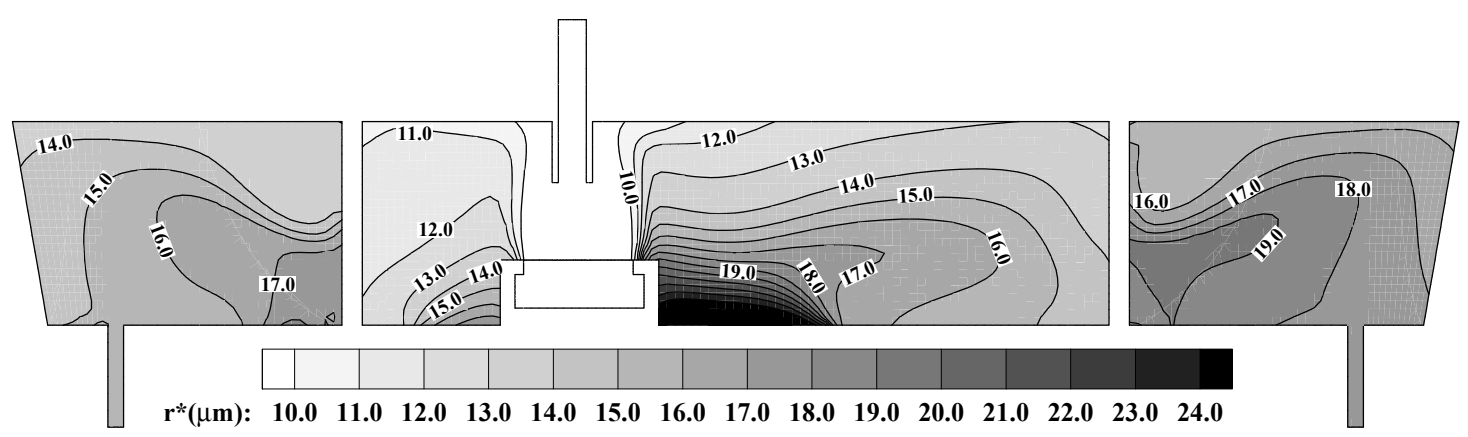

(a) A-A Section

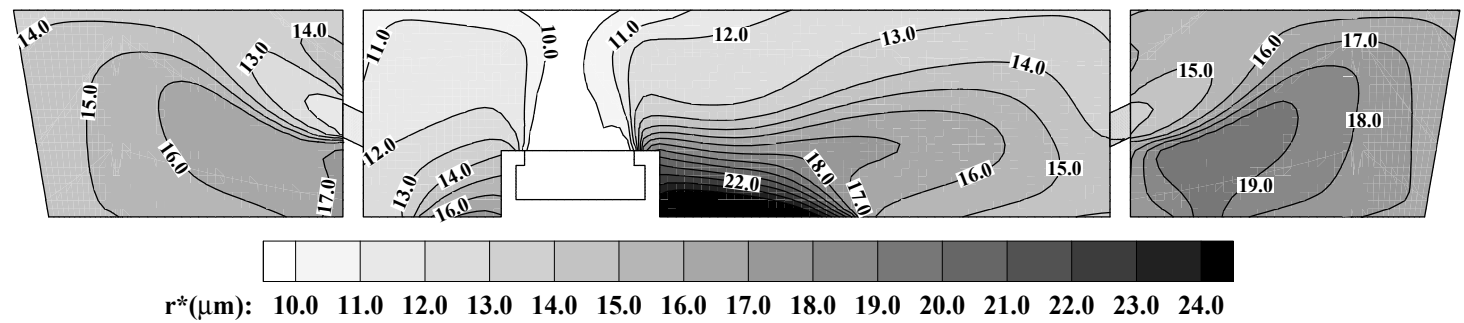

(b) B-B Section

Figure 13. Characteristic inclusion radius in the optimized tundish. 
Figures 14 and 15 show that the inclusion number density in the original tundish and optimized tundish has some features: (1) The inclusion number density decreases gradually when the fluid flows from the ladle shroud to the tundish outlet because some inclusions are removed by the slag layer or the tundish wall. (2) In the region between the two dams (or the two multi-hole baffle walls), the inclusion number density in the upper part is greater than that in the lower part, because the molten steel near the free surface is the fresh molten steel, and the inclusion number density is high in the fresh molten steel. (3) The inclusion number density above the outlet is less than that in the region between the ladle shroud and the dam (or the baffle wall), because the new big inclusions come from the collision aggregation among the inclusions, and the big inclusion is removed by the slag layer and the tundish wall. (4) The inclusion number density at the left outlet is less than that at right outlet, because the inclusion has more chances to be removed at the region between the ladle shroud and the right outlet.

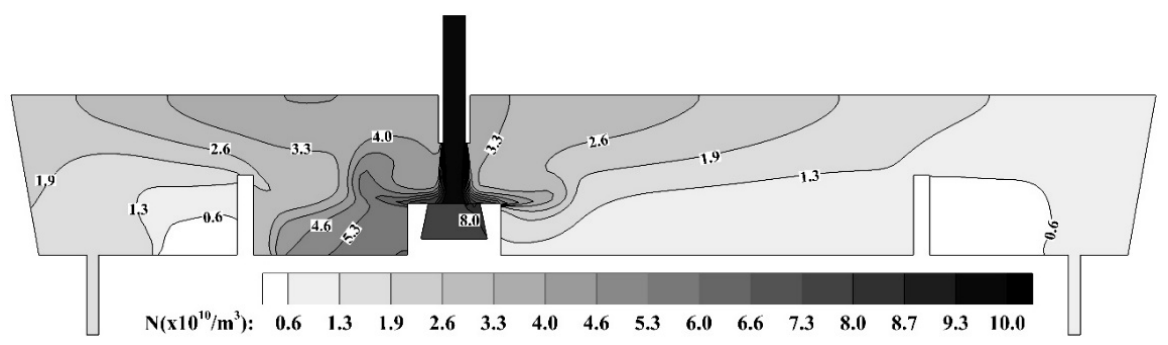

(a) A-A Section

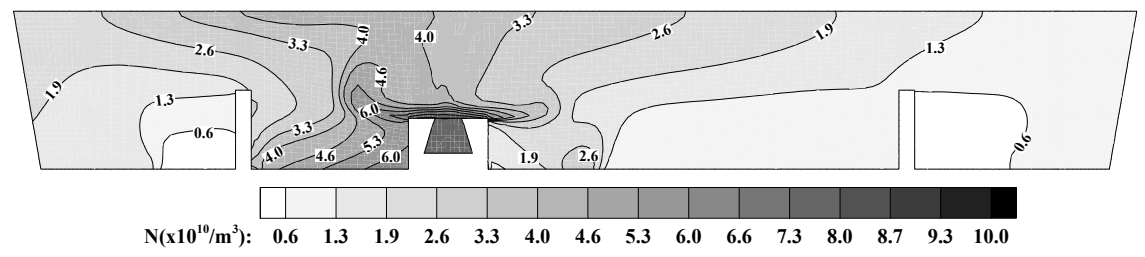

(b) B-B Section

Figure 14. Characteristic inclusion number density in the original tundish.

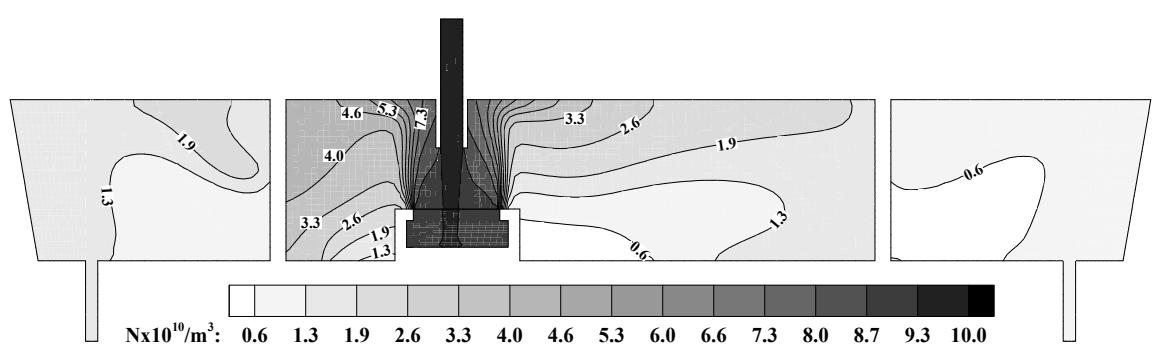

(a) A-A Section

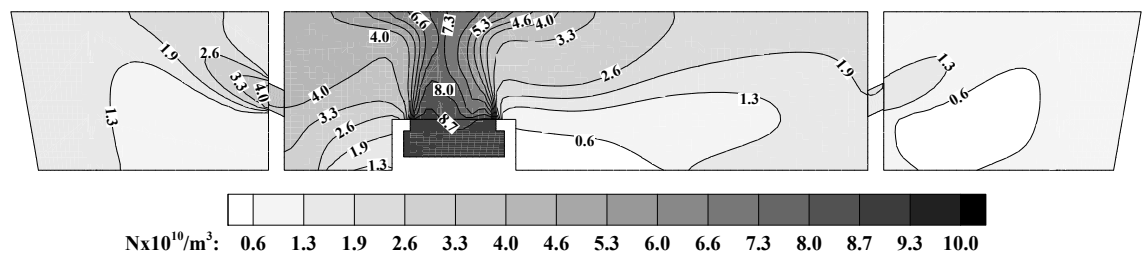

(b) B-B Section

Figure 15. Characteristic inclusion number density in the optimized tundish. 


\subsection{General Discussion}

Figures 4-15 show that the fluid flow, the heat transfer, and the inclusion distribution are asymmetric because the ladle shroud is not placed in the middle of the original and optimized tundish. In this way, it is necessary to realize the quasi-symmetry distribution in the current asymmetric tundish. In this guidance, the optimized tundish adopts two measurements. (1) Taking the centerline of the ladle shroud as the reference point, the square turbulence inhibitor has a small outlet at the left side and a large outlet at the right side in the optimized tundish. (2) Two baffle walls with the same guide-holes are applied to reduce the asymmetric effect of the ladle shroud on the transfer behavior on both sides of the optimized tundish.

Table 5, Figures 9-15 show that there are smaller differences of the mean residence times and the temperatures, and the inclusion size between two exits decreases in the optimized tundish. Such simulation results indicate that the optimized scheme can decrease the asymmetric distribution of physical parameters in the original scheme. Thus, industrial trial is proposed to verify the above ideas.

Tables 6 and 7 give the industrial result, the related tundish is shown in Figure 16. The temperature difference between two outlets is up to $8.7^{\circ} \mathrm{C}$ in the original tundish and is around $6{ }^{\circ} \mathrm{C}$ in the optimized tundish, but the predicted temperature difference is $6.8^{\circ} \mathrm{C}$ in the original tundish and $4.5^{\circ} \mathrm{C}$ in the optimized tundish. Several reasons lead to the difference between the predicted value and the experimental data. (1) There is measurement error for the temperature measurement by the thermocouple. (2) The values of the heat loss in Table 4 come from the literature, not the actual value in the current tundishes. (3) There are some assumptions in the mathematical model.

Table 6. The measured temperature of molten steel at different outlets in the original tundish.

\begin{tabular}{|c|c|c|c|c|c|}
\hline Temperature Measurement & $T_{\text {Outlet1 }}\left({ }^{\circ} \mathrm{C}\right)$ & $T_{\text {Outlet2 }}\left({ }^{\circ} \mathrm{C}\right)$ & $T_{\text {Average-Outlet1 }}\left({ }^{\circ} \mathrm{C}\right)$ & $T_{\text {Average-Outlet2 }}\left({ }^{\circ} \mathrm{C}\right)$ & $\Delta T=T_{\mathrm{Av}-1}-T_{\mathrm{Av}-2}\left({ }^{\circ} \mathrm{C}\right)$ \\
\hline \multirow{5}{*}{ The first casting } & 1590 & 1576 & \multirow{5}{*}{1568.7} & \multirow{5}{*}{1560} & \multirow{5}{*}{8.7} \\
\hline & 1562 & 1558 & & & \\
\hline & 1561 & 1550 & & & \\
\hline & 1562 & 1551 & & & \\
\hline & 1563 & 1558 & & & \\
\hline
\end{tabular}

Table 7. The measured temperature of molten steel at different outlets in the optimized tundish.

\begin{tabular}{|c|c|c|c|c|c|}
\hline Temperature Measurement & $T_{\text {Outlet1 }}\left({ }^{\circ} \mathrm{C}\right)$ & $T_{\text {Outlet2 }}\left({ }^{\circ} \mathrm{C}\right)$ & $T_{\text {Average-Outlet1 }}\left({ }^{\circ} \mathrm{C}\right)$ & $T_{\text {Average-Outlet2 }}\left({ }^{\circ} \mathrm{C}\right)$ & $\Delta T=T_{\mathrm{Av}-1}-T_{\mathrm{Av}-2}\left({ }^{\circ} \mathrm{C}\right)$ \\
\hline \multirow[t]{2}{*}{ The first casting } & 1562 & 1552 & \multirow[t]{2}{*}{1560} & \multirow[t]{2}{*}{1553} & \multirow[t]{2}{*}{7} \\
\hline & 1557 & 1555 & & & \\
\hline \multirow{3}{*}{ The second casting } & 1547 & 1546 & \multirow{3}{*}{1548.5} & \multirow{3}{*}{1543.5} & \multirow{3}{*}{5} \\
\hline & 1549 & 1540 & & & \\
\hline & 1549 & 1543 & & & \\
\hline
\end{tabular}

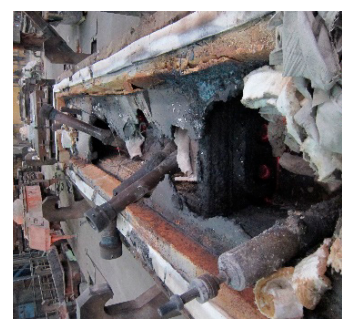

(a) optimized tundish

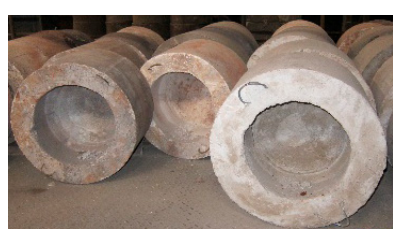

(b) original turbulence inhibitor

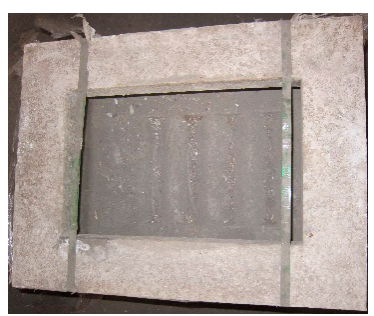

(c) optimized turbulence inhibitor

Figure 16. Industrial tundish.

Figure 10 shows that the inclusion removal rate is only $30.25 \%$ at the left outlet and $53.61 \%$ at the right outlet in the original tundish. Thus, it is necessary to increase the inclusion removal rate at the left outlet. Figure 11 shows that the inclusion removal rate is $35.14 \%$ at the left outlet and $51.47 \%$ at the right outlet in the optimized tundish. 
Table 8 indicates that the inclusion mass concentration at outlet 1 in the optimized tundish is less than that at outlet 1 in the original tundish, and the inclusion mass concentration at outlet 1 is greater than that at outlet 2 in the original tundish.

Table 8. Inclusion weight in steel by sample-electrolysing method.

\begin{tabular}{|c|c|c|c|c|c|}
\hline The Sample & $\begin{array}{l}\text { Original Sample } \\
\text { Weight (kg) }\end{array}$ & $\begin{array}{l}\text { Residual Sample } \\
\text { Weight (kg) }\end{array}$ & $\begin{array}{l}\text { Electrolytic Sample } \\
\text { Weight (kg) }\end{array}$ & $\begin{array}{c}\text { Inclusion (mg) } \\
80-140 \mu \mathrm{m}\end{array}$ & $\begin{array}{c}\text { Inclusion (mg) } \\
140-300 \mu \mathrm{m}\end{array}$ \\
\hline Outlet 1 in original tundish & 1.34 & 0.31 & 1.03 & 0.6 & 0.7 \\
\hline Outlet 2 in original tundish & 1.47 & 0.44 & 1.03 & 0.4 & 0.7 \\
\hline Outlet 1 in optimized tundish & 1.33 & 0.31 & 1.02 & - & 0.2 \\
\hline
\end{tabular}

\section{Conclusions}

(1) In the asymmetric two-strand tundish, decreasing the difference of the mean residence time between the two outlets can reduce the temperature difference effectively.

(2) The mean residence time of $352.4 \mathrm{~s}$ at the left outlet in the optimized tundish is $36.8 \mathrm{~s}$ greater than the mean residence time of $315.6 \mathrm{~s}$ at the left outlet in the original tundish. And the difference of mean residence time between the two outlets falls by $10.0 \%$ from $203.8 \mathrm{~s}$ to $183.5 \mathrm{~s}$.

(3) In the original tundish, the temperature of molten steel at the right outlet is less than that at the left outlet. The asymmetric turbulence inhibitor and the baffle wall with guided holes can reduce the difference of the temperature of molten steel between the two outlets effectively.

(4) In the original tundish, the inclusion removal rate at the right outlet is greater than that at the left outlet. The asymmetric turbulence inhibitor and the baffle wall with guided holes can prompt the inclusion removal rate at the left outlet in the optimized tundish.

Author Contributions: Author Contribution: Investigation, B.Y., G.X.; Methodology, B.Y., H.L.; Writing一original draft preparation, B.Y.; Writing-review and editing, Y.Z., H.Z.; Validation, G.X.; Project administration and funding acquisition, H.L.

Funding: This paper was supported by National Natural Science Foundation of China and Shanghai Baosteel (No. U1460108) and National Natural Science Foundation of China (No. 51574074).

Acknowledgments: The work is supported by National Natural Science Foundation of China and Shanghai Baosteel (No. U1460108) and National Natural Science Foundation of China (No. 51574074).

Conflicts of Interest: The authors declare no conflict of interest.

\section{References}

1. Mazumdar, D.; Guthrie, R.I.L. Physical and mathematical modelling of continuous casting tundish systems. ISIJ Int. 1999, 39, 524-547. [CrossRef]

2. Chattopadhyay, K.; Isac, M.; Guthrie, R.I.L. Effect of flow modifiers on liquid metal cleanliness in four-strand delta shaped bille caster tundish. Ironmak. Steelmak. 2012, 39, 454-462. [CrossRef]

3. Chattopadhyay, K.; Isac, M.; Guthrie, R.I.L. Physical and mathematical modelling of steelmaking tundish operations: a review of the last decade (1999-2009). ISIJ Int. 2010, 50, 331-348. [CrossRef]

4. Chang, S.; Cao, X.; Zou, Z.; Isac, M.; Guthrie, R.I.L. Microbubble swarms in a full-scale water model tundish. Metall. Mater. Trans. B 2016, 47, 2732-2743. [CrossRef]

5. Koizsch, R.; Odenthal, H.J.; Pfeifer, H. Concentration measurements in a water model tundish using the combined DPIV/PLIF technique. Steel Res. Int. 2007, 78, 473-481. [CrossRef]

6. Liu, J.; Yan, H.; Liu, L.; Wang, X. Water model of controlling vortex in tundish. J. Iron Steel Res. Int. 2006, 18, $18-22$.

7. Sheng, D.; Kim, C.S.; Yoon, J.K.; Hsiao, T.C. Water model study on convection pattern of molten steel flow in continuous casting tundish. ISIJ Int. 1998, 38, 843-851. [CrossRef]

8. Zhang, S.; Zhu, M. Water model study of removal mechanism of inclusion in continuous casting tundish. Acta Metall. Sin. 2007, 43, 1004-1008. Available online: http://www.ams.org.cn/CN/Y2007/V43/I9/1004 (accessed on 5 August 2019). (In Chinese). 
9. Godiwalla, K.M.; Sinha, S.K.; Sivaramakrishnan, C.S. Water model simulation of tundish flow under varying conditions. Steel Res. 1994, 65, 267-272. [CrossRef]

10. Alizadeh, M.; Edros, H.; Shafyei, A. Fluid flow and mixing in non-isothermal water model of continuous casting tundish. J. Iron Steel Res. Int. 2008, 15, 7-13. [CrossRef]

11. Miki, Y.; Thomas, B.G. Modeling of inclusion removal in a tundish. Metall. Mater. Trans. B 1999, 30, 639-654. [CrossRef]

12. Zhang, L.; Taniguchi, S.; Cai, K. Fluid flow and inclusion removal in continuous casting tundish. Metall. Mater. Trans. B 2000, 31, 253-266. [CrossRef]

13. Ling, H.; Zhang, L. Numerical simulation of the growth and removal of inclusions in the molten steel of a two-strand tundish. JOM 2013, 65, 1155-1163. [CrossRef]

14. Zhang, J.; Lee, H.G. Numerical modeling of nucleation and growth of inclusions in molten steel based on mean processing parameters. ISIJ Int. 2004, 44, 1629-1638. [CrossRef]

15. Zhao, L.; Liu, K.J. Study on inclusion behavior in tundish during continuous casting by mathematical model. Iron Steel Res. Int. 2002, 14, 19-24. [CrossRef]

16. $\mathrm{Xu}, \mathrm{K}$;; Thomas, B.G. Particle-size-grouping model of precipitation kinetics in microalloyed steels. Metall. Mater. Trans. A 2012, 43, 1079-1096. [CrossRef]

17. Ho, Y.H.; Hwang, W.S. Numerical simulation of inclusion removal in a billet continuous casting mold based on the partial-cell technique. ISIJ Int. 2003, 43, 1715-1723. [CrossRef]

18. Raghavendra, K.; Sarkar, S.; Ajmani, S.K.; Denys, M.B.; Singh, M.K. Mathematical modelling of single and multi-strand tundish for inclusion analysis. Appl. Math. Model 2013, 37, 6284-6300. [CrossRef]

19. Liu, Z.; Li, L.; Li, B. Large eddy simulation of transient flow, solidification, and particle transport processes in continuous-casting mold. JOM 2014, 66, 1184-1196. [CrossRef]

20. Javurek, M.; Gittler, P.; Rossler, R.; Kaufmann, B.; Presslinger, H. Simulation of nonmetallic inclusions in a continuous casting strand. Steel Res. Int. 2005, 76, 64-70. [CrossRef]

21. Cwudzinski, A. Numerical simulations and industrial experiments of liquid steel alloying process in one strand slab tundish. Ironmak. Steelmak. 2015, 42, 132-138. [CrossRef]

22. Cwudzinski, A. Mathematical modeling and industrial experiment of liquid steel flow in the three outlets continuous casting bloom tundish. Arch. Metall. Mater. 2013, 58, 1077-1083. [CrossRef]

23. Cwudzinski, A. Numerical, physical, and industrial experiments of liquid steel mixture in one strand slab tundish with flow control devices. Steel Res Int. 2014, 85, 623-631. [CrossRef]

24. Sahai, Y.; Emi, T. Melt flow characterization in continuous casting tundishes. ISIJ Int. 1996, 36, 667-672. [CrossRef]

25. Lei, H.; Jiang, J.; Yang, B.; Zhao, Y.; Zhang, H.; Wang, W.; Dong, G. Mathematical model for collision-coalescence among inclusions in the bloom continuous caster with M-EMS. Metall. Mater. Trans. B 2018, 49, 666-676. [CrossRef]

26. Yang, B.; Lei, H.; Bi, Q.; Xiao, Y.; Zhao, Y. Numerical simulation of collision-coalescence and removal of inclusions in a tundish. JOM 2018, 70, 2950-2957. [CrossRef]

27. Lei, H.; Wang, L.; Wu, Z.; Fan, J. Collision and coalescence of alumina particles in the vertical bending continuous caster. ISIJ Int. 2002, 42, 717-725. [CrossRef]

28. Zhang, Y.H.; Wu, W.F.; Huang, J. Numerical simulation research on flow behavior of T-type five strands asymmetric tundish with additional flow control devices. Foundry Technol. 2010, 31, 922-925.

29. Wang, Q.; Li, B.; Tsukihashi, F. Modeling of a thermo-electromagneto-hydrodynamic problem in continuous casting tundish with channel type induction heating. ISIJ Int. 2014, 54, 311-320. [CrossRef]

30. Cong, L.; Zhang, J.M.; Lei, S.W.; Li, M.K. Numerical simulation on tundish induction heating. Res. Iron Steel 2014, 42, 20-25.

31. Lei, H. New insight into combined model and revised model for RTD curves in a multi-strand tundish. Metall. Mater. Trans. B 2015, 46, 2408-2413. [CrossRef]

(C) 2019 by the authors. Licensee MDPI, Basel, Switzerland. This article is an open access article distributed under the terms and conditions of the Creative Commons Attribution (CC BY) license (http://creativecommons.org/licenses/by/4.0/). 